\title{
EDITORIAL
}

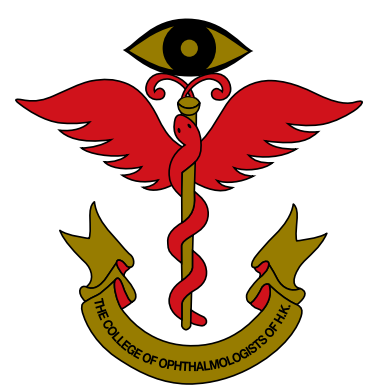

香 港 眼 科 醫 學 院

\section{Challenges that lie ahead}

Ian YH Wong, MBBS, M.Med (Oph)(Singapore), FRCSEd, FRCOphth, FCOphth HK, FHKAM (Ophthalmology) Department of Ophthalmology, The Hong Kong Sanatorium and Hospital

Correspondence and reprint requests:

Dr Ian YH Wong, Department of Ophthalmology, The Hong Kong Sanatorium and Hospital, 2 Village Road, Happy Valley, Hong Kong.

Email: ianyhwong@gmail.com

It has been my greatest honor and pleasure to have taken up the office of the Editor-in-Chief of the Hong Kong Journal of Ophthalmology (HKJO) since 2015. During the past two terms of service, we have seen leaps forward for our Journal. Some areas have had a facelift. For instance, HKJO has found its new home at hkjo.hk. Not only has this increased accessibility, it has also enabled authors to submit their manuscripts online. Since the launch of the website, HKJO has received 8362 visits from all over the world (as of 15 March 2019), including from the United States, India, China, the United Kingdom, Russia, and Singapore. Most visitors to the website are from Hong Kong (constituting around $30 \%$ of all visits), followed by the United States (11.8\%) and India (7.5\%) [Table and Figure]. We have also received submissions from different parts of the world. The original goal of setting up the website was to enhance international exposure of $\mathrm{HKJO}$ and to encourage submissions from outside of Hong Kong. I believe we have successfully achieved this goal. Although the setting up of the website was challenging, it was clearly the right decision. I wish to thank the Council of the College of Ophthalmologists of Hong Kong for endorsing this endeavor and for providing financial support. I would also like to acknowledge Dr Alvin $\mathrm{Au}$ Ka Hong for designing and setting up the website, and for providing technical support throughout the years.

Following the launch of the website, we had to find ways for our articles to be 'discoverable' by readers. Because HKJO is not indexed in MEDLINE, we made efforts to ensure the Journal was indexed in Google Scholar. Anyone searching Google Scholar can easily find our articles, and those who are interested are referred to our website so that the full article can be downloaded at no cost. Around $76 \%$ of visitors to our

\begin{tabular}{|lc|}
\hline $\begin{array}{l}\text { Table. Number of visits to the Hong Kong Journal of Ophthalmology } \\
\text { website (hkjo.hk) }\end{array}$ \\
\hline Geographical location & No. (\%) of visits \\
\hline Hong Kong & $2583(30.87)$ \\
\hline United States & $990(11.83)$ \\
\hline India & $630(7.53)$ \\
\hline United Kingdom & $489(5.85)$ \\
\hline Russia & $395(4.72)$ \\
\hline Singapore & $283(3.38)$ \\
\hline Indonesia & $216(2.58)$ \\
\hline Canada & $201(2.40)$ \\
\hline China & $193(2.31)$ \\
\hline
\end{tabular}

website were diverted from Google Scholar, whereas only 22\% accessed the website directly (as of 15 March 2019). This shows the importance of being indexed by a popular search engine, as it can boost the number of visitors to our website and hence enhance the impact of our articles.

The three most downloaded articles on our website are: 'Thyroid eye disease: a 2017 update from the first thyroid eye clinic in Hong Kong' by Chong et al, ${ }^{1}$ followed by 'Update on the management of non- infectious uveitis' by $\mathrm{Ng}$ et al, ${ }^{2}$ and 'Small incision lenticule extraction: a review' by Yung et al. ${ }^{3}$ May I take this opportunity to congratulate the authors on this achievement.

To encourage Fellows and trainees of the College to submit to HKJO, with generous support from the College and the Timothy Liu Kai Ching Memorial Fund, the Best Original 


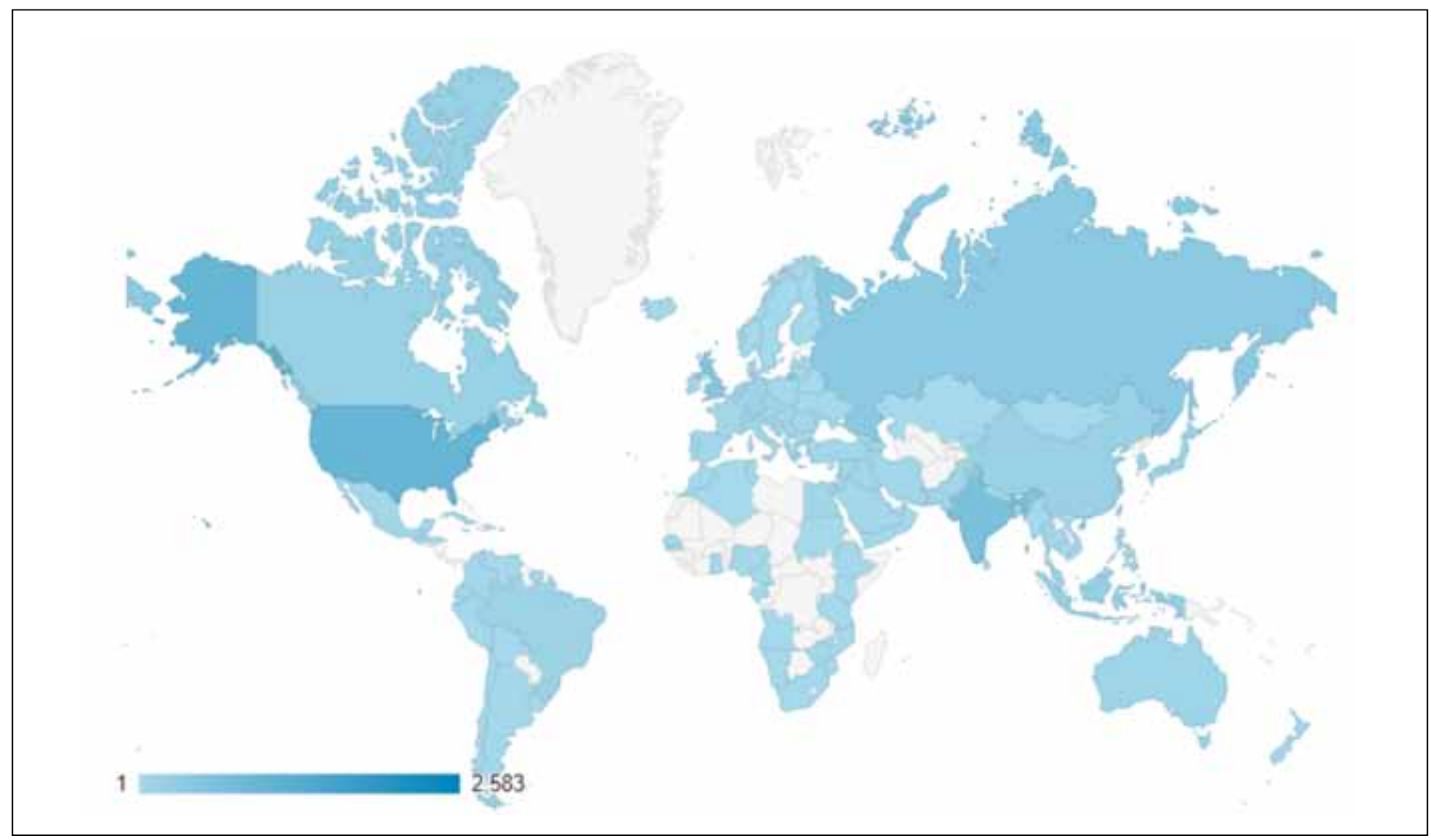

Figure. Frequency of visits according to the visitor's region.

Article Award was established in 2015. Original articles submitted to HKJO are evaluated by a panel appointed by the College Council, based on originality, novelty, clarity in presentation, and scientific impact of the results. Owing to the relatively low rate of submission, the Award is not given out yearly. I would like to take this chance to encourage more submissions from Fellows and trainees so as to make the selection process more competitive.

To be indexed by MEDLINE requires fulfilling several criteria. ${ }^{4}$ The journal should demonstrate high quality of editorial work, showing objectivity, credibility, and quality of its content. The journal should also provide information about the methods of article selection and external peer review, publication policy requiring adherence to ethical guidelines, and proper disclosure of financial interests where appropriate. ${ }^{4}$ The current Editorial Team has worked hard towards that goal. We truly believe that with collaborative efforts from all Fellows and Members of the College, HKJO will be indexed in MEDLINE one day.

This is the final issue for my current term of service as the Editor-in-Chief. I will step down after the upcoming Annual General Meeting of the College. I would like to show my heartfelt gratitude to all Editorial Board members and International Advisors for their continued support and input. I also wish my succeeding Editor-in-Chief every success, and I am sure he/she will bring HKJO to new heights.

\section{References}

1. Chong KKL, Lai THT, Chan R, Li CL, Young A. Thyroid eye disease: a 2017 update from the first thyroid eye clinic in Hong Kong. Hong Kong J Ophthalmol 2017;21:11-8.

2. Ng D, Mohamed S, Chu WK, Luk FOJ, Brelen M, Chan CKM. Update on the management of non-infectious uveitis. Hong
Kong J Ophthalmol 2016;20:95-105.

3. Yung W, Ng ALK, Chan TCY, Jhanji V, Wang Y, Cheng GPM, Woo VCP. Small incision lenticule extraction: a review. Hong Kong J Ophthalmol 2017;21:19-23.

4. Medicine USN. FAQ: Journal Selection for MEDLINEß Indexing at NLM. Available from: https://www.nlm.nih.gov/ lstrclj_sel_faq.html. Accessed 1 April 2019. 